\title{
VIVÊNCIAS DA EQUIPE DE ENFERMAGEM NO COTIDIANO DO SISTEMA PENAL
}

\author{
EXPERIENCES OF THE NURSING TEAM IN THE \\ ROUTINE OF THE CORRECTIONAL SYSTEM
}

\section{EXPERIENCIAS DEL EQUIPO DE ENFERMERÍA EN LA VIDA COTIDIANA DEL SISTEMA DE JUSTICIA PENAL}

\author{
Ana Amélia Melo Soares ${ }^{1}$ \\ Gabriela Miranda de Oliveira Castro ${ }^{2}$ \\ Isabelle Elias Monteiro de Almeida ${ }^{3}$ \\ Luciana Alves Silveira Monteiro ${ }^{4}$ \\ Lilian Machado Torres 5
}

Como citar este artigo: Soares AAM, Castro GMO, Almeida IEM, Monteiro LAS, Torres LM. Vivências da equipe de enfermagem no cotidiano do sistema penal. Rev baiana enferm. 2020;34:e34815.

\begin{abstract}
Objetivo: compreender o cotidiano vivido pela equipe de Enfermagem no sistema penal. Método: pesquisa qualitativa realizada com quatro enfermeiros e dois técnicos de Enfermagem de um Centro de Remanejamento Prisional, em Minas Gerais, Brasil. Os dados foram coletados por meio de entrevista entre junho e julho de 2018, e analisados com base no referencial de Minayo. Resultados: emergiram quatro categorias temáticas: "percepção do cuidado de Enfermagem à pessoa privada de liberdade"; "dificuldades para prestar assistência no presídio"; "sensação de invisibilidade do cuidado de Enfermagem no sistema prisional"; e "ambiguidade de sentimentos ao cuidar da saúde no sistema prisional." Conclusão: o ambiente prisional não favorece ações concretas de promoção da saúde e prevenção de agravos. O enfrentamento viria com educação permanente, reuniões clínico-administrativas, além da construção de protocolos e diretrizes que sistematizem e sustentem as práticas.
\end{abstract}

Descritores: Assistência à saúde. Enfermagem. Prisões. Prisioneiros.

Objective: to understand the everyday life lived by the Nursing team in the correctional system. Method: qualitative research conducted with four nurses and two Nursing technicians from a Prison Resettlement Center, in Minas Gerais, Brazil. Data were collected through an interview between June and July 2018, and analyzed based on the framework of Minayo. Results: four thematic categories emerged: "perception of Nursing care with the person deprived of freedom"; "difficulties to provide assistance in prison"; "feeling of invisibility of Nursing care in the prison system"; and "ambiguity of feelings of the health care in the prison system". Conclusion: the prison environment does not encourage concrete actions for health promotion and disease prevention. Coping strategies would come with permanent education, clinical and administrative meetings, in addition to the construction of protocols and guidelines that systematize and support the practices.

Descriptors: Delivery of Health Care. Nursing. Prisons. Prisoners.

\footnotetext{
Enfermeira. Enfermeira na Santa Casa de Misericórdia de Piumhi. Piumhi, Minas Gerais, Brasil. https://orcid.org/0000-0003-3137-4630.

Enfermeira. Enfermeira no Hospital Felício Rocho. Belo Horizonte, Minas Gerais, Brasil. https://orcid.org/0000-000 I-7672-7765.

Enfermeira. Pesquisadora independente. Belo Horizonte, Minas Gerais, Brasil. https://orcid.org/0000-000 I-5006-9776.

Enfermeira. Mestre em Enfermagem. Professor Assistente I da Faculdade de Ciências Médicas de Minas Gerais. Belo Horizonte, Minas Gerais, Brasil. https://orcid. org/0000-0002-1071-9946.

5 Enfermeira. Doutora em Ciências. Pesquisadora independente. Belo Horizonte, Minas Gerais, Brasil. lilian.torres0806@gmail.com.br. https://orcid.org/0000-0002$7510-7078$.
} 
Objetivo: comprender la vida cotidiana vivida por el equipo de Enfermería en el sistema de justicia penal. Método: Investigación cualitativa realizada con cuatro enfermeros y dos técnicos de Enfermería de un Centro de Reasentamiento de Prisiones, en Minas Gerais, Brasil. Los datos fueron recolectados por medio de una entrevista entre junio y julio de 2018, y analizados con base en el referencial de Minayo. Resultados: cuatro categorias temáticas surgieron: "la percepción de la atención de Enfermería a la persona privada de libertad"; "las dificultades para prestar asistencia en la prision"; "la sensación de invisibilidad de los cuidados de Enfermería en el sistema penitenciario"; $y$ "la ambigüedad de los sentimientos en el cuidado de salud en el sistema penitenciario". Conclusión: el ambiente carcelario no fomenta acciones concretas para la promoción de la salud y prevención de enfermedades. El enfrentamiento vendría con la educación permanente, reuniones clínicas y administrativas, además de la construcción de pautas y protocolos para sistematizar y sostener las prácticas.

Descriptores: Prestación de Atención de Salud. Enfermería. Prisiones. Prisioneros.

\section{Introdução}

Estima-se que a população prisional mundial tenha alcançado 11 milhões de indivíduos e, em 15 anos, é esperado um aumento desse quantitativo entre $25 \%$ e $30 \%{ }^{(1-2)}$.

Ressalta-se que a maioria dos detentos está concentrada nos Estados Unidos, seguido da China, da Rússia e do Brasil, cujos números ultrapassam 700 mil presos, o que representa um acréscimo da ordem de $70 \%$ em relação ao total registrado na década de 1990 . Tal contingente coloca o Brasil em $4^{\circ}$ lugar na lista das maiores populações prisionais do mundo, com ritmo acelerado de crescimento e condições precárias, apesar da divulgação de recentes e vultosos investimentos governamentais ${ }^{(1,3)}$.

A superlotação é uma realidade mundial $^{(2)}$ e, nos presídios brasileiros, supera em 61,3\% a capacidade do sistema. Essa população é composta por pessoas jovens de 18 a 24 anos (31\%), de 25 a 29 anos (25\%), e acima de 30 anos (44\%). Torna-se possível constatar o cenário subumano e vulnerável e refletir sobre a complexidade da situação vivida pelas pessoas encarceradas e pelos gestores responsáveis pelo espaço, recursos, eficiência e programas educacionais e reabilitadores ${ }^{(2,4-5)}$.

No Brasil, na Costa do Marfim, nos EUA e na França, por exemplo, a efetivação da saúde nas prisões permanece um expressivo desafio, num contexto essencialmente voltado para a segurança. Observa-se acesso limitado à saúde desde antes do confinamento e piora da situação nos cárceres, principalmente em relação à tuberculose (TB), infecção pelo Vírus da Imunodeficiência Humana (HIV) e transtornos mentais ${ }^{(6)}$.
Urge uma política pública que considere a inclusão social das pessoas privadas de liberdade e que reoriente as ações e os serviços de saúde em direção à promoção da saúde, além da prevenção e da reabilitação, quando instalados os $\operatorname{agravos}^{(5,7-8)}$.

O ambiente nas prisões, mais que a própria população, impulsiona, de uma forma geral, a incidência de $\mathrm{TB}^{(9)}$. No sistema prisional brasileiro estima-se que a taxa de incidência de TB seja 27 vezes maior que na população total do país ${ }^{(10)}$. Nos países de baixa e média renda, os dados sobre transtornos mentais em presídios são pouco conhecidos, apesar de maior incidência quando comparados com a população em geral e com países de alta renda ${ }^{(11)}$. Não se pode deixar de ressaltar os custos relacionados, sobretudo quando poucos governos apresentam relatórios claros e consistentes sobre os custos dos serviços de saúde nesse cenário ${ }^{(12)}$.

Outra questão, não menos importante, refere-se aos profissionais de saúde envolvidos e que se encontram diante de uma via de mão dupla: a lealdade à pessoa humana, como um dever primário, e à instituição, em relação aos aspectos de segurança ${ }^{(13-14)}$. No entanto, as práticas da equipe que atua em presídios devem procuram suprir as demandas de saúde detectadas ${ }^{(15)}$.

Do ponto de vista histórico, a Enfermagem vem se adaptando aos cenários atuais nos quais sua presença é demandada, como no sistema penal $^{(14)}$. A equipe multidisciplinar percebe a importância do enfermeiro nos presídios, a fim de otimizar o acesso das pessoas às ações e intervenções de saúde ${ }^{(16)}$. Trata-se de um profissional 
considerado eixo fundamental para a promoção, manutenção e recuperação da saúde durante a privação da liberdade ${ }^{(15)}$.

Dessa forma, torna-se imprescindivel tal objeto de estudo, isto é, a compreensão, na perspectiva do profissional de Enfermagem que atua nos presídios, das práticas cotidianas vivenciadas no atendimento à saúde da população carcerária. Analisar o vivido, baseado na abordagem qualitativa, permite dar maior visibilidade a experiências que qualificam a assistência, desde a formação de profissionais até a gestão do cuidado.

O objetivo deste estudo foi compreender o cotidiano da equipe de Enfermagem que atua no sistema penal.

\section{Método}

Pesquisa exploratória, descritiva, com análise qualitativa e baseada em ferramentas que devem ser consideradas para a construção do saber científico $^{(17)}$. Estudo desenhado e preparado com base nos critérios consolidados para relatos de pesquisa qualitativa (COREQ) ${ }^{(18)}$.

O local do estudo foi um Centro de Remanejamento Prisional, em município da região metropolitana de Belo Horizonte, Minas Gerais, Brasil. A unidade estadual abriga 1.200 detentos, embora sua capacidade seja para 400 reclusos. O estudo foi autorizado pela Secretaria de Estado da Administração Prisional e pelo Comitê de Ética em Pesquisa (CEP) da Faculdade Ciências Médicas de Minas Gerais, sob o Parecer de n. 2.640.390.

A coleta dos depoimentos realizou-se entre junho e julho de 2018. Participaram quatro enfermeiros, um deles, do sexo masculino e os demais, do sexo feminino, e dois técnicos de Enfermagem, ambos do sexo feminino. A média de idade dos participantes foi de 38,3 anos, todos com vínculo profissional formal de servidor público do Estado de Minas Gerais e, em média, com 4,3 anos de trabalho na instituição. Os critérios de inclusão foram: ser profissional habilitado (enfermeiro ou técnico de Enfermagem) e servidor estadual efetivo. Como critério de exclusão, adotou-se apenas a ausência do profissional por férias ou licença no período da pesquisa, evento que envolveu apenas um membro da equipe, técnico de Enfermagem.

Após os entendimentos preliminares com a direção do presídio, os profissionais foram apresentados aos pesquisadores que, de forma presencial, realizaram o convite para participação no estudo. Em seguida, procedeu-se a assinatura no Termo de Consentimento Livre e Esclarecido (TCLE) pelos participantes, após as explicações sobre o estudo, suas razões, interesse dos pesquisadores e objetivos propostos. As entrevistas foram gravadas após autorizaçao dos depoentes. As entrevistas foram agendadas e realizadas por apenas três dos pesquisadores envolvidos, à época estudantes, do sexo feminino, do último período do Curso de Enfermagem, treinadas e sob a orientação de dois professores, mestre e doutor, respectivamente. Não havia conhecimento e/ou relações prévias entre os entrevistadores e os participantes.

No setor administrativo do presídio foi definido um espaço físico para os depoimentos e cada entrevista durou, em média, 30 minutos, com a presença apenas do profissional e um dos pesquisadores. Os participantes foram identificados por código alfanumérico para presevação do sigilo, utilizando-se as letras E para enfermeiros e TE para técnicos de Enfermagem, seguidas de números arábicos, definidos individualmente.

O roteiro de entrevista continha questões que abordavam a percepção da assistência à saúde prestada às pessoas privadas de liberdade e de como se sentiam, além dos pontos positivos e negativos experimentados no cotidiano. As questões foram apresentadas aos participantes no momento da entrevista e não houve retorno aos profissionais ou repetição de encontros.

O referencial de Minayo foi utilizado para a análise de conteúdo dos depoimentos que compreendeu a população disponível, mesmo havendo a saturação de dados, por ocasião do $4^{0}$ e $5^{\circ}$ depoimentos, discutida entre entrevistadores e professores orientadores. A fase de análise compreendeu a organização dos depoimentos para facilitar a identificação das semelhanças e diferenças em cada conjunto de temas abordados pelos participantes. Em seguida, os conjuntos foram reorganizados para possibilitar 
a classificação dos conteúdos emergentes e favorecer a compreensão do que aparece de forma enfática ou reiterada. Assim, surgiu o significado expresso pelos depoentes ${ }^{(17)}$.

As transcrições não foram apresentadas e/ou devolvidas aos participantes e os temas emergentes, resultantes dos depoimentos foram comparados com a literatura científica, após a sua síntese. Ao final do estudo, os resultados foram apresentados aos gestores da unidade prisional e parte do estudo foi divulgado no $8^{\circ}$ Congresso Ibero-Americano em Investigação Qualitativa (CIAIQ) ${ }^{6}$.

\section{Resultados}

Os resultados tiveram seu conteúdo analisado e emergiram quatro categorias: Percepção do cuidado de Enfermagem à pessoa privada de liberdade; Dificuldades para prestar assistência no presídio; Sensação de invisibilidade do cuidado de Enfermagem no sistema prisional; e, Ambiguidade de sentimentos ao cuidar da saúde no sistema prisional.

\section{Percepção do cuidado de Enfermagem à pessoa privada de liberdade}

Na visão dos participantes, os cuidados prestados não acontecem segundo as normas e regulamentações profissionais. Ressaltaram a necessidade imperiosa de melhorias para qualificar os serviços técnicos, no âmbito institucional:

\begin{abstract}
À noite não existe muito contato com o detento, pois não existem atendimentos, só em casos de urgência. Eu estou sozinha no período noturno e, como técnica de Enfermagem, fico um pouco limitada. Só consigo fazer uma avaliação e, se necessário, encaminhar o detento. (TE2).
\end{abstract}

A assistência não é adequada em relação ao que os detentos precisam. A estrutura física é inadequada e os insumos são precários. (E2).

Entretanto, pontos positivos no âmbito cuidativo foram relacionados:

As vantagens existentes são os testes rápidos, os exames de sangue e a prioridade no agendamento de consultas especializadas. (E1).
Os profissionais de Enfermagem destacaram as dimensões humana e holística presentes nos cuidados, independente das questões legais, mas não deixaram de citar a sensação de impotência:

Eu vejo o recluso e a saúde dele, independente do artigo penal [artigo que levou à privação da liberdade]. (TE1).

Fazemos pouco em relação ao que poderia ser feito, considerando que falta um protocolo clínico para o sistema [prisional], que direcione as atitudes e condutas. Não possuímos nem mesmo o Protocolo Operacional Padrão e quem está de fora não imagina. Eu não imaginava as dificuldades que encontraria e que fossem tão dificeis essas questões. (E1).

Os entrevistados elencaram as ações de cuidado à saúde das pessoas, perceberam características humanizadoras nas intervenções, entretanto, assinalaram inadequações que poderiam ser corrigidas por meio de protocolos e determinações governamentais. Como consequência, emergiram problemas no cotidiano.

\section{Dificuldades para prestar assistência no presídio}

A estrutura física da unidade e seu funcionamento operacional estão em desacordo com o preconizado pelas resoluções dos órgãos competentes, segundo os depoentes: As dificuldades para o atendimento são a falta do ma-
terial [médico-hospitalar] e o espaço físico. O ideal seria
um espaço para ambulatório, uma sala de curativos,
um local adequado para armazenamento de insumos e
medicaçôes, além de salas divididas para atendimentos
individuais. Ainda são necessários macas, lugar para a
espera do recluso, espaço para realizar infusâo intrave-
nosa e sala de observação. (E3).

Não temos médico diariamente, faltam medicamentos e um ambiente com estrutura mais adequada e ampla. Assim a assistência poderia ser melhor, com médico diariamente, boa aparelhagem, sala de vacinação. Isso faria o atendimento ser adequado e evitaria os deslocamentos. (E4).

Outras dificuldades relacionam-se ao aparelhamento e provisionamento de insumos, de forma suficiente e permanente:

\footnotetext{
Não temos oxigênio, eletrocardiograma [referindo-se ao eletrocardiógrafo], desfibrilador. Veja que o aparelbo de pressão, o oxímetro e o glicosímetro são todos meus. Na unidade não é realizada manutenção e calibragem dos aparelhos, trimestralmente. (E2).
} 
No caso das medicações, na maioria das vezes, não recebemos a quantidade correta, ou então, chega muita medicação com prazo de vencimento próximo ao final. (E3).

A equipe de Enfermagem especificou os problemas relacionados ao encaminhamento do recluso de sua cela para o atendimento na enfermaria:

São muitas as dificuldades para o preso chegar até a enfermaria. Os agentes penitenciários retiram o preso da cela e o colocam em um lugar chamado "corró", que é uma cela utilizada para a triagem. O recluso aguarda muitas horas ou, às vezes, nem chega à enfermaria. Pode ficar dias aguardando e, quando recebe o atendimento, os sintomas já passaram, ou utilizaram remédio de outros colegas. Algumas vezes, a febricula passa a ser febre alta, com risco de convulsão. Teria que escoltar e encaminhar rapidamente, mas a justificativa é a falta de agente [penitenciário] disponivel e a suposição do recluso estar simulando e forçando atendimento desnecessário. (E2).

Igualmente, foram elencadas dificuldades para encaminhar o recluso às unidades de saúde externas ao presídio, quando da necessidade de atendimento:

\begin{abstract}
Nós prestamos o atendimento em nível ambulatorial. Os casos mais simples nós conseguimos resolver, mas, se houver necessidade de uma internação, não conseguimos atender, pois há demora para encaminhar o recluso para atendimento fora da prisão. (E4).
\end{abstract}

Temos alguns entraves com certos agentes, com o pessoal da escolta. Muitas vezes, o problema é a falta de carro e a falta de agente [penitenciário]. Se for urgência e não tiver carro disponivel, pode demorar, pois o acompanhamento é necessário. (E3).

Os profissionais enumeraram algumas melhorias na assistência à saúde que poderiam acontecer, apesar das dificuldades presentes no cotidiano prisional. Questionaram a interferência dos agentes penitenciários sobre as ações e os procedimentos que compõem o cuidado de Enfermagem, assim como expuseram a sua percepção sobre o olhar dos demais profissionais.

\section{Sensação de invisibilidade do cuidado de Enfermagem no sistema prisional}

Os participantes narraram a interferência dos agentes penitenciários, de forma direta, no atendimento de Enfermagem prestado e questionaram tal forma de agir:

\footnotetext{
Nunca vi o serviço de Enfermagem ser tão questionado como no sistema prisional. Os profissionais que não são da área da saúde opinam muito sobre o atendimento de Enfermagem. (E1).
}

Há muitas dificuldades e questionamentos do pessoal de segurança. Nem sempre a avaliação da Enfermagem basta para que o recluso receba o atendimento demandado. Na maioria das vezes, o cuidado depende da "avaliação" dos agentes [penitenciários] e, para eles, o problema apresentado pode esperar. Dessa forma, o recluso não recebe a atenção no momento necessário. (E2).

Um dos profissionais afirmou sentir-se melindrado pela forma como é observado no seu cotidiano:

Eventualmente sinto constrangimento em relação à equipe de segurança que nos ronda. Nós não somos bem vistos aqui e, em certos procedimentos, eu percebo um olhar diferente. Fico constrangida, pois eles não entendem o lado profissional. (TE1).

Os participantes verbalizaram inadequação na prestação do cuidado e referiram as dificuldades intervenientes em sua prática diária, com destaque para as interferências e os questionamentos por parte dos agentes penitenciários. Como consequência, descreveram as emoções geradas e que se relacionam à desvalorização profissional.

\section{Ambiguidade de sentimentos ao cuidar da saúde no sistema prisional}

Acréscimo de conhecimento técnico e tirocínio profissional, decorrentes do perfil dos diagnósticos definidos e cuidados assistenciais exigidos nos presídios, foram reconhecidos pelos depoentes:

A unidade é muito rica em relação à parte clínica, patologias, pois cada dia é uma coisa nova. Você não sabe o que te espera e, assim, o sistema faz você estudar $e$ conbecer novos assuntos. (E4).

Atender a população carcerária é conbecimento que você leva pra si. Sobre a diversidade de patologias e casos com que me deparo, posso afirmar que não teria tal oportunidade em lugar algum. (E2).

Além disso, reconheceram e agradeceram a oportunidade de cuidar de pessoas privadas de liberdade, da melhor forma encontrada, mediante as dificuldades:

Como ponto positivo, percebo um certo retorno. O recluso
tem mais gratidão pelo nosso trabalbo, são mais maleá-
veis e colaborativos em certos procedimentos. São passí-
veis de comunicação e não possuem aquela resistência
que a comunidade tem. (TE1).

Contudo, os profissionais vivenciam uma variedade de sentimentos. Descreveram o medo, a 
pressão e a desconfiança, que contribuem para o acuamento e sensação de pouca segurança:

\begin{abstract}
Todos que trabalham aqui são suspeitos. Nesses casos de aparelhos eletrônicos nas celas, a maior suspeita recai sobre os funcionários, por isso não atendo sozinha. Não pretendo trabalhar na unidade por muito tempo, vejo como uma passagem, um aprendizado, pois é adoecedor trabalhar a vida toda desse jeito, nessa pressão psicológica, desconfiança e suspeição. Mas, a nossa profissão tem disso, a Enfermagem é uma mistura de amor édio. (E1).

A todo momento somos suspeitos, quem está nesse ambiente trabalhando é suspeito, já que dentro das celas pode ter muita droga e celulares. (TE2).
\end{abstract}

Sentir-se pressionado e acuado também emergiu em outros depoimentos:

\begin{abstract}
O serviço aqui suga você e meu medo é uma rebelião, um motim, ser feito de refém. Esses aparelhos [referindo-se aos aparelhos celulares] que acham dentro das galerias, é um problema difícil. Temos que estar sempre alertas, ativos. Pode acontecer da equipe realizar um atendimento, o recluso achar que não foi adequado e pedir alguém para fazer justiça, fora do presídio. (E3).
\end{abstract}

Tenho receio, pois não conhecemos as pessoas e a sua natureza. Caso um recluso não concorde com o atendimento que realizei, posso até ser agredida, moral ou fisicamente, lá fora. Aqui dentro, temos que tratar bem, com educação, com profissionalismo para não ter esse tipo de problema na vida pessoal. Eu gosto de trabalhar aqui, mas minha maior frustração é a falta de estrutura e a omissão com o sistema prisional. Eu tenho amor e gosto da profissão. Mas, tem que ter emocional, pegamos de tudo aqui e quem não tem boa estrutura emocional, não fica. (E4).

Os resultados apontaram a percepção de um cuidado profissional à saúde aquém do preconizado, muito em função das dificuldades destacadas e dos sentimentos vividos. Pontos positivos e vantagens do trabalho no presídio foram enumerados, principalmente, os relacionados à humanização. O reconhecimento e a valorização foram avaliados apenas pelo olhar dos detentos. Apesar das emoções vivenciadas de medo, pressão e desconfiança os participantes percebem ganhos na competência do conhecimento.

\section{Discussão}

Os cuidados à saúde prestados aos detentos não foram percebidos como executados de forma adequada e de acordo com o preconizado pelas normas e regulamentações da profissão, apesar do reconhecimento do esforço para que ocorram como entendem ser o adequado e legal.
De fato, a complexidade do ambiente faz despontar desafios para o acesso à saúde nos presídos, modelo que não pode estar isolado dos sistemas regionais e nacionais de atenção e que permita o avanço da independência dos profissionais em ambiente de correição prisional, com vistas à qualidade assistencial ${ }^{(7,13)}$. O olhar para a saúde dessa população ainda está pautado no modelo curativista, baseado nas queixas, pelas quais a decisão de atendimento passa, primeiramente, pelos agentes penitenciários em função da questão de segurança ${ }^{(8,19)}$, evidenciado pela atenção centrada em demandas de carater emergencial ou cuidado especializado.

No entanto, a equipe de Enfermagem afirmou realizar os cuidados em saúde da melhor maneira possível, por considerar que todos os privados de liberdade são seres humanos com os direitos de cidadãos. Mesmo assim, percebe-se nos depoimentos o sentimento de impotência diante do que é necessário fazer e que não se consegue, em decorrência das limitações reconhecidas. Estudo de tendências temporais, de dados secundários das unidades prisionais brasileiras entre 2007 e 2014, confirma altas taxas de doenças nos presídios, dados que reclamam ações governamentais nos âmbitos de saúde e justiça $^{(7)}$. Mesmo diante das dificuldades, os profissionais se esforçam em seu cotidiano e, por isso, estão expostos a todo tipo de pressão, o que demanda dos administradores intervenções que promovam qualidade de vida no trabalho e impactem positivamente no comprometimento organizacional, com vistas à melhoria da assistência à saúde das pessoas privadas de liberdade $^{(8,20)}$. Ressalte-se que a suposta autonomia relatada, mesmo que em dimensões aquém do necessário ou possível, denota o contrário, isto é, a falta de autonomia para as decisões sobre o cuidado em saúde no presídio, mesmo tendo em vista a Lei do Exercício Profissional de Enfermagem, que garante esse desempenho.

Os aspectos qualitativos e quantitativos de insumos, equipamentos e recursos humanos, apontados como inadequados ou escassos, constituem fatores geradores de altos níveis de estresse nos profissionais e reduzem a qualidade do cuidado prestado. Influem, outrossim, sobre a segurança 
dos trabalhadores que os identificam ou os associam a riscos à sua integridade ${ }^{(19)}$. Dessa forma, a adequação à legislação vigente é essencial para a execução de ações eficazes e envoltas em segurança ${ }^{(21)}$. Os resultados também apontaram a ausência de protocolos e diretrizes específicas que orientem as práticas profissionais em Enfermagem, nos cenários de privação de liberdade. Percebe-se o anseio pelo direcionamento no agir cotidiano que, por sua vez, poderia repercutir em sentimentos de invisibilidade e desconfiança. A equipe precisa discutir em que bases podem e querem cuidar, se é possível sistematizar suas ações e definir os pressupostos teóricos de sustentação. Tal perspectiva não pode ficar invisível aos profissionais e, menos ainda, aos gestores da instituição que se propõe recuperar pessoas que transgrediram leis e normas sociais.

No contexto analisado, a decisão para o atendimento fora do presídio e a indisponibilidade de escolta para o transporte dos detentos foram observados como fatores externos e que impactam de forma incisiva os cuidados de Enfermagem. A literatura demonstra que, em casos de urgência, a demora no atendimento, em quaisquer situações, pode comprometer o resultado esperado ${ }^{(19)}$. Da mesma forma, a cooperação entre as equipes de saúde e de segurança reveste-se dos aspectos éticos necessários para garantir o atendimento, respeitando-se os diferentes papéis profissionais, porém voltados para a mesma direção ${ }^{(13)}$. Estas são dificuldades de âmbito normativo, operacional, estrutural e administrativo, reconhecidas pelos profissionais de Enfermagem, que carecem ser consideradas pelos gestores, uma vez que implicam diretamente na qualidade, eficácia e efetividade do cuidado prestado e na garantia da segurança das pessoas privadas de liberdade e dos próprios trabalhadores.

A despeito do trabalho em equipe, os depoentes deixaram clara a sua percepção de invisibilidade no sistema prisional, apesar do constante olhar de vigilância e interferência durante os procedimentos de Enfermagem. Trata-se de outra forma de invisibilidade, aquela que se refere ao profissionalismo, à consideração laboral, à importância de cada elemento no contexto.
Pesquisas ressaltam que a desvalorização de competências pessoais acarreta sentimentos negativos, como impotência e desestímulo, quando não se consegue assistir os necessitados ${ }^{(22)}$, além da desmotivação e possibilidade de desenvolvimento de psicopatologias ${ }^{(8)}$. Ademais, os profissionais de saúde nos sistemas prisionais deveriam ser considerados e ouvidos por ocasião da elaboração de estratégias que reduzam disparidades, bem como treinados para lidar com as peculiaridades e especificidades da saúde nas prisões $^{(7)}$. Percebeu-se, por vezes, o desejo de não permanecer na instituição por um longo período.

Há que se considerar que os enfrentamentos e conflitos diários, mesmo que surdos, influenciam a prática cotidiana, ao esbarrarem na dimensão ética do cuidado de Enfermagem que sustenta as relações e as tomadas de decisão. Daí a necessidade de se cuidar de quem cuida e de fomentar a educação permanente.

Mesmo diante das amarras para cuidar, os trabalhadores apontaram ser imprescindível garantir a assistência adequada e ampla, que tem seu início em cuidados básicos e na educação para a saúde. De fato, os relatórios oficiais em diversos países apontam parte dos custos prisionais relacionados aos cuidados primários em saúde ${ }^{(12)}$. E estudos defendem que a atenção à saúde das pessoas privadas de liberdade deveria estar direcionada para o nível primário, que identifica problemas, realiza diagnóstico, planeja e implementa a assistência. A Enfermagem também pode contribuir, ao proporcionar cuidado autônomo e não fragmentado, conforto e bem-estar, somados ao resgate do sentido da existência humana e à redução da discriminação e/ou de preconceitos ${ }^{(8,19,23)}$. Os resultados ressaltaram que procedimentos simples e pontuais resolveriam parte dos problemas enfrentados, quando a demora para o atendimento ou o encaminhamento externo é evidente por problemas administrativos ou de invisibilidade, mas verbalizados como questões de segurança. Desejo de melhorias no cuidado prestado levantam pontos de reflexão sobre o agir de todas as equipes institucionais, que demandam, 
por sua vez, o olhar aguçado dos dirigentes de presídios e gestores públicos.

Nesse contexto, emergiram sentimentos e emoções, positivos e negativos, vivenciados no contato com detentos, dentre eles a desconfiança, a pressão e o medo. Estudo sobre a visão dos trabalhadores de Enfermagem expõe uma mistura de sentimentos na rotina dos profissionais em presídios, sejam eles pela própria emoção despertada pela profissão ou pelo tipo de pessoa e/ou ambiente, no qual se envolvem no trabalho. Isso pode desencadear elementos facilitadores ou dificultadores do processo de cuidar em saúde ${ }^{(19)}$. Além disso, quando o ambiente caracteriza-se pela superlotação, o moral dos profissionais pode ser afetado, além das preocupações com controles e segurança ${ }^{(2)}$. No entanto, não são todos os detentos que estabelecem ameaças e riscos imediatos para a equipe de Enfermagem. Como é difícil estabelecer diferenças, o profissional mantém-se, frequentemente, em estado de defesa e vivacidade, que se traduz na tensão ambiental ${ }^{(14)}$, amplamente destacada pelos participantes, nas diversas situações relatadas. No entanto, é preciso questionar em que momento haveria a discussão, tanto em âmbito institucional quanto no âmbito das políticas públicas, sobre os caminhos de enfrentamento, para que os fenômenos identificados como prejudiciais possam ser transformados ou minimizados. Do contrário, apenas as emoções e as dificuldades continuarão a ser divulgadas nas comunicações científicas.

Fato é que, no ambiente prisional, quase tudo representa possibilidade da emoção denominada, em geral, como medo de algo. Neste cenário, a pressão vivenciada, a violência e a vigilância constante são fatores que afetam a saúde mental dos profissionais ${ }^{(22,24)}$. Ressalta-se que vivenciar constrastes entre cuidar e cuidar com segurança da custódia, influencia sobremaneira a forma como se presta a assistência de Enfermagem $^{(14)}$. Por outro lado, em momento algum foram evidenciadas sugestões de melhoria em relação aos fatores geradores de medo e insegurança, o que aponta para a ausência de discussão da questão na equipe de Enfermagem e junto às demais equipes, principalmente a de segurança, geradora de atitudes que promovem o medo, na visão dos profissionais.

Não obstante todos os dificultadores e os sentimentos expostos pelos depoentes e corroborados pela literatura, evidenciou-se, também, a vivência de emoções positivas, as quais não poderiam deixar de ser apresentadas. Gratidão e reconhecimento foram destacados, em função da possibilidade de suprir necessidades e ajudar pessoas marginalizadas. Outro fato mencionado relaciona-se à aprendizagem ímpar, consequência da diversidade de quadros clínicos e patologias existentes no presídio. Tal resultado é destacado por autores que buscaram encontrar significados em circunstâncias difíceis, em estudo realizado com profissionais de saúde em prisões, que apontou como um dos atributos positivos a variedade de doenças tratadas. De fato, trabalho significativo e sentimentos de apoio, reclamados pelos depoentes, são dimensões que precisam ser consideradas na restauração da relevância do cuidado à saúde das pessoas privadas de liberdade $^{(25)}$. Entretanto, não houve menção a grupos de discussão clínica para atualizar os conhecimentos sobre as patologias no presídio. Igualmente, os profissionais não citaram a busca, individual ou coletiva, de atualização dos casos novos, o que leva à inferência da não percepção de necessidade de educação permanente.

O estudo apresenta limitações por ter sido realizado em apenas uma unidade prisional, com número reduzido de profissionais de Enfermagem, porém, longe de inferências para generalizar os resultados encontrados, buscou-se a compreensão das práticas cotidianas do cuidado de Enfermagem na realidade do cenário pesquisado.

\section{Conclusão}

A pesquisa permitiu compreender as vivências da equipe de Enfermagem no sistema prisional, sob a perspectiva dos próprios profissionais envolvidos no cuidado em saúde. O cotidiano vivido pela equipe de Enfermagem junto às pessoas privadas de liberdade 
Ana Amélia Melo Soares, Gabriela Miranda de Oliveira Castro,

evidenciou a percepção de que melhorias no sistema concorreriam para qualificar e atender as regulamentações voltadas para a assistência no contexto das prisões.

Os resultados destacaram o esforço para se atingir dimensões humana e holística, apesar das dificuldades identificadas que se relacionam à estrutura física inadequada, ao aparelhamento e provisionamento de artigos médico-hospitalares necessários ao cuidado em saúde, assim como o dimensionamento, maior disponibilidade e treinamento de recursos humanos.

Urge que as políticas públicas considerem implementar ações mais concretas, voltadas à promoção da saúde e prevenção de doenças, com a detecção precoce dos principais agravos decorrentes do encarceramento. Outros encaminhamentos necessários seriam a definição clara de papéis profissionais nos presídios, a educação permanente, as reuniões clínicas, o trabalho em equipe e a gestão eficiente. Dessa forma, os profissionais envolvidos estariam valorizados e com o olhar mais abrangente sobre as pessoas privadas de liberdade em um cenário hostil, que não pode representar hostilidade no fazer cotidiano.

\section{Colaborações}

1 - concepção, projeto, análise e interpretação dos dados: Ana Amélia Melo Soares, Gabriela Miranda de Oliveira Castro, Isabelle Elias Monteiro de Almeida, Luciana Alves Silveira Monteiro e Lilian Machado Torres;

2 - redação do artigo e revisão crítica relevante do conteúdo intelectual: Luciana Alves Silveira Monteiro e Lilian Machado Torres;

3 - aprovação final da versão a ser publicada: Luciana Alves Silveira Monteiro e Lilian Machado Torres.

\section{Referências}

1. Walmsley R. World prison population list [Internet]. 11a ed. London: Institute for Criminal Policy Research; 2016 [cited 2020 Mar 4]. Available from: http://www.prisonstudies.org/sites/default/files/ resources/downloads/world_prison_population_ list_11th_edition_0.pdf

2. MacDonald M. Overcrowding and its impact on prison conditions and health. Int J Prison Health. 2018;14(2):65-8. DOI: 10.1108/IJPH-04-2018-0014

3. Brasil. Ministério da Justiça e Segurança Pública. Levantamento Nacional de Informações Penitenciárias (IFOPEN). Atualização de Junho de 2016 (Internet). Brasília (DF); 2017 [cited 2020 Mar 4]. Available from: http://depen.gov.br/ DEPEN/noticias-1/noticias/infopen-levantamentonacional-de-informacoes-penitenciarias-2016/ relatorio_2016_22111.pdf

4. Ribeiro AP. Prisons viewed from an interdisciplinary standpoint. Ciênc saúde coletiva. 2017;22(2):663-4. DOI: 10.1590/1413-81232017222.23942015

5. Cordeiro EL, Silva TM, Silva LSR, Pereira CEA, Patrício FB, Silva CM. Epidemiological profile of carceraries: notified pathologies. Av enferm. 2018;36(2):170-8. DOI: 10.15446/av.enferm. v36n2.68705

6. Minayo MCS, Gualhano L. Saúde nas prisões: avaliações, políticas e práticas. Ciênc saúde coletiva [Internet]. 2016 Jul [cited 2020 Mar 4];21(7). Available from: http://www.scielo.br/scielo.php?script=sci_ arttext_pr\&pid=\$1413-81232016010800001\&lng=e $\mathrm{n} \& \mathrm{nrm}=\mathrm{iso \& t} \operatorname{lng}=\mathrm{pt}$

7. Job Neto F, Miranda RB, Coelho RA, Gonçalves CP, Zandonade E, Miranda AE. Health morbidity in Brazilian prisons: a time trends study from national databases. BMJ Open. 2019;9:e026853. DOI: 10.1136/ bmjopen-2018-026853

8. Santana JCB, Reis FCA. Perception of The Nursing Team About Health Care in The Prison System. J res: fundam care online. 2019 Oct/Dec;11(5):1142-7. DOI: $10.9789 / 2175-5361.2019 . v 1115.1142-1147$

9. Mabud TS, Alves MLD, Ko AI, Basu S, Walter KS, Cohen T, et al. Evaluating strategies for control of tuberculosis in prisons and prevention of spillover into communities: An observational and modeling study from Brazil. PLoS Med. 2019;16(3):e1002764. DOI: 10.1371/journal.pmed.1002764

10. Brasil. Ministério da Saúde. Guia sobre gênero, HIV/AIDS, coinfecções no sistema prisional [Internet]. Brasília (DF); 2012 [cited 2020 Mar 4]. Available from: https://www.unodc.org/documents/ lpo-brazil/Topics_aids/Publicacoes/GUIA_ SOBRE_GENERO_HIV_em_prisoes_2012.pdf

11. Baranyi G, Scholl C, Fazel S, Patel V, Priebe S, Mundt AP. Severe mental illness andsubstance 
use disorders in prisoners in low-income and middle-income countries: a systematic review and meta-analysis of prevalence studies. Lancet Glob Health. 2019;7(4):e461-e471. DOI: 10.1016/ S2214-109X(18)30539-4

12. Sridhar S, Cornish R, Fazel S. The Costs of Healthcare in Prison and Custody: Systematic Review of Current Estimates and Proposed Guidelines for Future Reporting. Front Psychiatry. 2018;9:716. DOI: $10.3389 /$ fpsyt.2018.00716

13. Pont J, Enggist S, Stöver $\mathrm{H}$, Williams B, Greifinger R, Wolff $H$. Prison Health Care Governance: Guaranteeing Clinical Independence. Am J Public Health. 2018;108(4):472-6. DOI: 10.2105/AJPH.2017.304248

14. Santos FS, Cavalcanti Valente GS, Souza LMC, Caldeira dos Santos MLS, Silva dos Santos I, Schwartz MP. Cuidados de enfermería en situación de cárcel según Waldow: entre lo profesional y lo expresivo. Enferm glob. 2013;12(31):290-315. DOI: 10.6018/eglobal.12.3.149531

15. Barbosa ML, Medeiros SG, Chiavone FBT, Atanásio LLM, Costa GMC, Santos VEP. Ações de enfermagem para as pessoas privadas de liberdade: uma scoping review. Esc Anna Nery 2019;23(3):e20190098. DOI: 10.1590/21779465-EAN-2019-0098

16. Wong I, Wright E, Santomauro D, How R, Leary C, Harris M. Implementing two nurse practitioner models of service at an Australian male prison: A quality assurance study. J Clin Nurs. 2018;27(1-2):e287-e300. DOI: 10.1111/jocn.13935

17. Minayo MCS. Análise qualitativa: teoria, passos, fidedignidade. Ciênc saúde coletiva. 2012;17(3): 621-6. DOI: 10.1590/S1413-8123201200 0300007

18. Tong A, Sainsbury P, Craig J. Consolidated criteria for reporting qualitative research (COREQ): a 32 item checklist for interviews and focus groups.
Ins J Qual Health Care. 2007;19(6):349-57. DOI: 10.1093/intqhe/mzm042

19. Santos FJ, Cardoso DSA, Brêda MZ, Costa LMC. Salud en las Prisiones: lo que hablan los trabajadores de enfermería. Cul Cuid. 2015;19(41):114-25. DOI: 10.14198/cuid.2015.41.14

20. Karaaslan A, Aslan M. The Relationship Between the Quality of Work and Organizational Commitment of Prison Nurses. J Nurs Res. 2019 Jun;27(3):e25. DOI: 10.1097/jnr.0000000000000286

21. Barbosa ML, Celino SDM, Oliveira LV, Pedraza DF, Costa GMC. Primary health care of convicts in the penitentiary system: subsides for nursing performance. Esc. Anna Nery. 2014 Dec;18(4):586-92. DOI: 10.5935/1414-8145. 20140083

22. Barbosa ML, Menezes TN, Santos SR, Olinda RA, Costa GMC. The quality of life of health professionals working in the prison system. Ciênc saúde coletiva. 2018;23(4):1293-302. DOI: 10.1590/1413-81232018234.09292016

23. Silva AAS, Sousa KAA, Araújo TME. Nursing assistance systematization in a prison unit underpinned by Orem Theory. Rev enferm UFSM. 2017;7(4):725-35. DOI: 10.5902/2179769222076

24. Santiago E, Zanola PC, Hisamura Junior RS, Silva IYM. The feeling of fear in daily work in prison surveillance and its impact on the subjectivity of penitentiary agents. Cad psicol soc trab. 2016;19(2):161-75. DOI: 10.11606/issn.19810490.v19i1p161-175

25. Stephenson AL, Bell N. Finding meaningful work in difficult circumstances: A study of prison healthcare workers. Health Serv Manage Res. 2019;32(2):69-77. DOI: 10.1177/0951484818787698

Recebido: 7 de dezembro de 2019

Aprovado: 27 de fevereiro de 2020

Publicado: 2 de abril de 2020

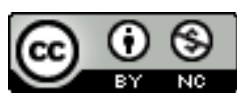

A Revista Baiana de Enfermagem utiliza a Licença Creative Commons - Atribuição-NãoComercial 4.0 Internacional. https://creativecommons.org/licenses/by-nc/4.0/ Este artigo é de acesso aberto distribuído sob os termos da Licença Creative Commons (CC BY-NC). Esta licença permite que outros remixem, adaptem e criem a partir do seu trabalho para fins não comerciais. Embora os novos trabalhos tenham de lhe atribuir o devido crédito e não possam ser usados para fins comerciais, os usuários não têm de licenciar esses trabalhos derivados sob os mesmos termos. 